\title{
Educational Technologies in Work with Gifted Students
}

\author{
Marina Ivleva \\ Department of Social Philosophy \\ Peoples' Friendship University of Russia \\ 6 Miklukho-Maklaya Street \\ Moscow, Russia \\ marinanonna@yandex.ru
}

\begin{abstract}
This paper considers the most popular, optimal and effective programs for the education and development of gifted children from the point of view of achieving the set goals. This article substantiates the relevance of such work and reviews the state of research in this area. The use of the technological approach has allowed solving the problem of creating the typology of extremely diverse forms and types of analyzed programs, referring to their underlying learning models, which include the learning objectives, the method of instruction, the forms in which it is implemented, instructional techniques and specific instructional methods. Special attention is paid to the study of the importance of a teacher in the implementation of such programs. The paper specifies tasks of the teacher and the criteria for their selection, the role models with reference to which the collaboration between parents and teachers can be built on. Finally, the paper presents the list of the most interesting programs as a result of studying the technological principles of certain concept representatives and the means that they actually use in the process of teaching and educating gifted children.
\end{abstract}

Keywords-gifted children; training and development programs; educational technology; technological approach; model of education; teachers of gifted children

\section{INTRODUCTION}

In the field of giftedness, there is now a paradoxical situation: the practice of teaching and developing gifted children far outstripped the theory [1]. This corresponds, on the one hand, to the tendency in the development of psychological and pedagogical research, where the scope of the rights and duties of applied studies in the field of giftedness has significantly expanded, and, on the other hand, to the reality of social life itself, in which the significance of gifted people has become not only conscious but also adequately estimated. The scientific community recognized the need to intensify work in the field of our interest, also for reasons unrelated to science. In particular, F.Barron states that talents would not be wasted if they were viewed as a

This paper is financially supported by the Ministry of Education and Science of the Russian Federation under the program on the improvement of The Peoples' Friendship University (RUDN University) competitiveness among the world's leading research and education centers in the 2016-2020 (The Agreement number 02.A03.21.0008). national product, an irreplaceable resource [2].

Modern teaching programs for gifted children are characterized by a wide distribution, a wide variety of forms and varieties. The diversity of experimental results and positions used in these programs is striking. This situation is caused by the mixture of different theoretical principles peculiar to many developers within the framework of the same research. In particular, all programs for American gifted preschoolers use provisions from different conceptual models (Karnes, Williams) [3] [4]. By the way, the development of conceptual models, on the basis of which programs for the education of gifted children are being created, is another significant trend of modern foreign applied research of giftedness. It is believed that on this basis, you can offer the most individualized program, more consistent and better organized than traditional ones. The use of the theoretical basis, which is the conceptual model, helps teachers approach their work more professionally and responsibly, and parents evaluate the child more realistically. Despite this, a number of programs still have inadequate conceptualization, which both domestic and foreign researchers point out

A review of the existing programs of education and development for gifted children makes it possible to raise the question of their typology on the basis of a technological approach, which means the analysis of the most popular and optimal learning models, including the teaching method, the forms in which it is implemented, pedagogical tools and specific pedagogical methods. The educational technology in the scientific literature is understood as a complex consisting of a certain representation of planned learning outcomes, means of diagnosing the current state of trainees, a set of learning models, criteria for choosing the optimal model for these specific conditions [5]. Obviously, the model of training in this complex is central.

Based on the learning models, it is possible to resolve the inevitable problems associated with the process of individualization and differentiation of programs for gifted children. Many authors note that intragroup differences of gifted children are not so essential to make it impossible to transfer strategies and teaching methods to different groups of gifted people. That is, programs developed for healthy 
gifted children are also applicable in teaching children who have sensory or physical disabilities [6]. It is much more important to recognize the fundamental inapplicability of programs for secondary students in the practice of working with gifted children because of their excessive standardization, traditionality, limitations in various frameworks (including age) and, at times, conservatism. As for the conceptual models, a large number of programs for teaching gifted children have been created on their basis. Researchers find it difficult to name their exact number, especially since this is not necessary. There is no reliable data about the advantages of this or that model, and the number of programs shows only their popularity and adaptability. In addition, some models have quite common concepts as their theoretical basis (for example, the concept of J. Gilford's structure of intelligence), which were well methodically worked out and mastered by teachers as early as the time of their own education. For example, the most popular conceptual models chosen by compilers of the programs for gifted preschoolers and those in the elementary schools in the USA (such as The Free Class and SOI (Structure of Intellect) by J. P. Guilford, The Training Goals Taxonomy by B. S. Bloom, Three Types of Enrichment of the Curriculum by J. S. Renzulli), often use the F. Williams' cognitive-affective model and the three-level model of creative teaching by D. Treffinger [7] [8] [9] [10] [11]. Based on them are the projects RAPYD1 (for gifted preschoolers with sensory or physical defects (J. Gilford's Structure of Intellect), and RAPYD 2 (Free class by J. Guildford), as well as the developed specific programs (AWARE by P. Elardo \& M. Cooper; IEP by A. Baldwin, G. Gear \& L. Lucito; ASTOR by M. Shure, G. Spivack \& M. Jaeger).

In our country, the models of thematic interdisciplinary integration by J. Dewey, V. P. Vakhterov were used to develop a holistic program for gifted children of grades 1-9 [12] [13].

\section{METHODICAL INSTRUMENTS IN THE PROGRAMS FOR GIFTED STUDENTS}

Let's turn to the analysis of the methodical instruments of the programs, which include not only the methodology for selecting trainees, but also the teaching methods and methodical materials. A lot of researchers note that teachers pay insufficient attention to this side of the program, focusing on the result of training [14]. In this area, there are often discussions about which teaching methods are most suitable for gifted children, whether traditional methods can be used, or they need adaptation, whether special methods of teaching gifted children should be created, whether one should follow one method of instruction, or are complex methods most suitable. T. Newland tried to answer some of the questions posed [15]. He also formulated the basic requirements for the methods of teaching gifted children: they should promote the acquisition of knowledge, correspond to the level of child's development and to the specifics of the learning situations; reflect the way of developing high cognitive abilities of the child and provide a transition from the perceptual level of cognition to higher conceptual levels. According to his confession, it is difficult to single out any method most suitable for gifted children. However, in the case of adaptation, any teaching method can be used in working with gifted children, although some methods are more suitable for this than others are.

Some researchers have already made their choice in favor of one method. Thus, J. Kagan, J. Feldhusen, D. Treffinger for stimulating active research activity of gifted students offer the method of discovery (self-learning) [16] [17] [18]. In their opinion, this method contributes to the increase of the child's involvement in the educational process, which leads to better assimilation. It also stimulates the child's intellectual efforts, increases his self-confidence and fosters a certain independence in his views and actions. In particular, according to D. Treffinger's model of creative learning, there are three levels of this process, each of which has its own goals and teaching methods [18] The initial level is aimed at the development of divergent functions (originality, semantic and figurative flexibility, the ability to produce a variety of ideas, to see the object from a new angle); the second level at the development of creative solutions to problems with the help of high-level intellectual processes; the latter - at child's carrying out independent, self-directed research of real problems that children choose, based on their capabilities and needs. Only this way the process of the discovering the surrounding world, its cognition and self-knowledge through the means of creative thinking is realized.

Mention should be made of the focus of some programs on the implementation of these goals through such methods as providing a favorable atmosphere, developing the curiosity of the child through enriching the environment with new subjects and incentives, encouraging child's original statements, using divergent type questions, giving children the opportunity to actively ask questions, using personal creative approach to problem solving.

For developing creative abilities, the methods of teaching with the help of reactions to the results of actions, actions and observation of behavior as a whole have also proved useful. Among the methods of stimulating creative thinking for gifted children we also highlight the removal or shift of time constraints in the types of activity that are most interesting to children, creating an atmosphere of openness and freedom, when the teachers encourage the spontaneous expression of thoughts and feelings, the desire to be different from others, reducing the level of anxiety and stress.

Here comes the idea by N. B. Shumakova who offers to provide methodically the process of creative and intellectual development of gifted children [19] [20]. She believes that such a possibility is created by a combination of various methods of creative learning with scientific methods of cognition. The latter provides for an active research position of the trained gifted child, to whom the teacher gives assistance, directing his investigative search. It is this approach that overcomes the gap between the content of the training program and its focus on developing creative thinking.

Another way to overcome the gap typical for many foreign programs was proposed by the authors of the joint 
Russian-American program, who added to the available deductive and problem methods in the arsenal of S. Kaplan a problem-dialogical method of instruction, which allowed to include in the learning process the lost link in generating the problem [21].

Thus, for the creative development the actual point is the very process of gifted child's participation in research, experimentation, search and finding new ways of developing the surrounding world.

A number of researchers have in mind another line of development for gifted children, namely an affective one, which involves not only the solution of special problems, but also special methods of this solution. K. Abroms and J. Gollin, for example, are sure that the most important tasks in the development of affective entities are the formation of a positive self-concept and self-esteem, the understanding of others and their acceptance, social competence [22]. As a methodical guide, she offers a set of activities, materials and topics aimed at creating a favorable atmosphere in the classroom, taking into account individual differences in children's behavior, verbal and non-verbal abilities. This is the "role-playing" lesson (the mission is "Birthday" by J. Flavell, P. Botkin, C. Fry, J. Wright, P. Jarvis, "interpersonal relationship test" K. Abroms, J. Gollin, or the stimulation of children's cooperation (the organization of games that unite children of different ages, sending a gifted child to another age group), or role-playing games (puppet shows, a test for determining the ability of preschoolers to resolve interpersonal problems (PIPS) or the test "What will be further"), etc. [23] [24]. In other programs, the emotional self-expression is the means of developing the creative potential. Thus, E. L. Yakovleva convincingly proved that the development of psychological prerequisites, the leadership talent promotes manifestation of creativity as a personal characteristic [25]. In her program of students' creative development, children are given opportunities to identify and manifest their own individuality in various areas using the following material-dramatization of situations invented by children or taken from life or fiction, various games, including conflict situations, resolution of problem situations using a variety of ways of emotional response, methods of teaching children to recognize their own sensations of all sensory modalities and verbal expression

Summing up the analysis of the methods used in applied studies of specialists in the field of giftedness, it should be recognized that they are no less diverse and original than the objects they are aimed at. This advantage, however, does not remove some of the comments caused by the insufficient connection of the content of the programs with their methodical support. Moreover, not only the creators of programs, but also their executors, are guilty. We are talking, of course, about teachers.

\section{TEACHERS OF THE GIFTED: TACTICAL TASKS AND SELECTION}

The role of educators in the implementation of programs and their final result, according to J. Nelson and D. Cleland, is a more important factor than the materials and methods they use [26]. The authors argue that it is in the teacher's hands that the fate of a gifted child is located, since the teacher creates conditions for the development of selfconfidence, creativity, success and achievements, interests and abilities, inspiring the student, encouraging, stimulating him, or destroying, ignoring, inhibiting, emasculating and discouraging him. These strategies are oppositely directed, but are encountered equally often.

Defining the tactical tasks of the teacher, the authors of the programs offer several options. The teacher can act as the initiator, mentor, guru, presenter (first option) or subordinate, performer, slave (second option) or companion, advisor, partner (third option). The choice of the role depends on the objectives of the program, which, in turn, are based on a certain theoretical basis. In the already mentioned conceptual models, the principles and essence of the program, as well as the standards that are subject to observation and evaluation, are clearly indicated. Accordingly, teachers are limited to these frameworks, although they remain free to choose a conceptual model or program. In the programs developed on the basis of the "Free class" model, the teacher actively cooperates with the trainees, giving them complete freedom in choosing the subjects of study, determining the intensity and duration of studies, planning their time, and provides the assistance if necessary. Unconventional use of the curriculum, school hours, facilities and staff of the school makes certain demands on the teacher. In particular, he must have organizational skills, ingenuity, tolerance and talent. In other programs organized on the basis of the "SOI" model, the teacher himself develops individual detailed programs and lesson plans, which are then discussed and adjusted on a daily basis. The teacher prepares methodical materials, in cooperative with children educational activity directs its course, stimulates activity and independence of children.

In some programs, the qualities necessary for a teacher working with gifted children are specially stipulated. So, the head of the program "Astor" for intellectually gifted children from four to ten V. Enrlich compiled a list of these qualities and tried to clarify it, by comparing it with the opinion of the teachers [27]. In most points, coincidences were found, especially with respect to such qualities as vigor, disposition towards children, warmth, high intelligence and the sense of humor. J. S. Renzulli marked the following qualities: intelligence above the average level, perseverance and purposefulness, as well as creativity [28].

If we summarize all approaches to the choice of criteria for the selection of teachers, mention should be made of their dependence on understanding the giftedness, the program's goals, the cultural, national, religious characteristics of the participants. All available selection criteria can be divided into personal and professional qualities, and the question of the predominant importance of the first or the second group is still relevant and open, although there are experimental data confirming their equivalence [29].

Attention is also drawn to the emphasis in many programs on the need for special training or retraining of teaching staff. The matter is that some pedagogical institutes and colleges include in their programs training courses for 
teachers to work with gifted children. However, their number is so insignificant that it can not meet the needs of society in specialists of this kind. The way out can be found in the system of additional education or advanced training of pedagogical personnel, as it is indicated, in particular, by $\mathrm{M}$. Karnes [29].

Another important issue is the cooperation of specialists and parents of gifted children. Here, experts show complete unanimity, arguing that this cooperation is important in terms of determining the goals that are set for the child, and the ways to achieve them. This cooperation largely influences the completeness of the child's realization of his own potential [30]. C. Takacs even suggested several variants of role models based on which parents' interaction with teachers in the preparation and implementation of training programs can be built [31]. All five models (lawyer, guide, mentor, classroom assistant and assistant in program development) are designed to help avoid many problems that children, their parents and teachers may face.

\section{EVALUATION OF THE EFFECTIVENESS OF THE PROGRAM FOR GIFTED STUDENTS}

Even a well-written program can have a different degree of efficiency. This depends on a number of reasons, among which the main place is given to the presence of an evaluation system in it. According to this system, the following can serve as criteria for assessing effectiveness: achieving the goals set, the attitude of the children towards it, the parents' opinion, the satisfaction of all participants with the results achieved. In particular, N. B. Shumakova laid a comprehensive criterion for evaluating the program effectiveness that includes experimental data on the dynamics of development of gifted children as a result of eight years of training under the "Gifted Child" program and studying the adequacy of the program to the needs and capabilities of gifted children from the point of view of children themselves [32], [33]. For these purposes, they studied the students 'attitudes toward learning by this program through analyzing students' interest in learning and its dynamics during the most "dangerous" secondary school age, as well as the degree of satisfaction with learning by the program for students with different levels of giftedness.

The results of the study, carried out with the help of the special questionnaire "Choice of the method of training", indicate a positive attitude towards learning by the experimental program among the majority of respondents, which was reflected in a high percentage of positive responses to each item of the questionnaire, in the degree of satisfaction with the learning process. And although the obtained data did not allow to reveal the age-related trends in the dynamics of interest in learning, they confirmed the reliably high effectiveness of this program.

In the program of creative development of the personality by E. Yakovleva, the criterion for its effectiveness was the changes in the intellectual and personal spheres of children, and their creativity measured with the help of Torrens test [34]. Similar is the approach of the developers of the programs AWARE and RAPYD II M. Shure, G. Spivack, M .Jaeger [35].

\section{CONCLUSION}

Based on the technological orientations of the representatives of these or those concepts, the means which are really involved in the process of teaching and educating gifted children, it is worth outlining the most interesting programs such as the Program of creative development of the gifted students by A. M. Matiushkin, the experimental Russian-American program to train gifted children of 6-8 years based on the program of S. Kaplan; the program of interdisciplinary training Gifted Child of N. B. Shumakova; the Free Class program of J. Guilford; the Taxonomy of the learning objectives by B. Bloom; the Cognitive-affective model of M. Williams; the original programs by J. Renzulli, M. Carne, D. Treffinger, etc. These programs deserve attention not only from the methodical point of view, but also as the most effective, productive, and, furthermore, extremely widespread and popular.

\section{REFERENCES}

[1] M.L. Ivleva, V. Yu. Ivlev, The principal approaches of modern psychology to constructing the giftedness, Proceedings of the 2017 Sedond International Conference on Contemporary Education, Social Sciences and Humanities (ICCESSH 2017), Part of the series ASSEHR, Moscow, Russia, Vol. 124, pp.1176-1180.

[2] F. Barron, Putting creativity to work // R.Sternberg \& T.Tardiff (Eds). The nature of creativity. Cambridge: Cambridge Press, 1988, pp.7698.

[3] M. Karnes \& Associates, Preschool talent checklists manual. Urbana Il.: Publication Office, Institute for Child Behavior \& Development, 1978.

[4] F. Williams, Classroom ideas for encouraging thinking \& feeling. Buffalo NY: DOK Publishers, 1970.

[5] V. V. Guzeev, Educational technology: from admission to philosophy. M.: Sept., 1996, pp. 8-9.

[6] M. Karnes \& Associates, Factors associated with underachievement \& overachievement of intellectually gifted children. Exceptional Children, 1961, 28, pp. 167-175.

[7] J. P. Guilford, The nature of human intelligence, N.Y.: McGraw-Hill, 1967.

[8] B. S. Bloom, Developing talent in young people, New York: Ballenting Books. 1985.

[9] J. S. Renzulli, The three-ring conception of giftedness: A developmental model for creative productivity // Sternberg R.I., Davidson J.E. (eds.). Conceptions of giftedness. Cambridge: Cambr. Univ. Press, 1986, pp. 53-92.

[10] F. Williams, Classroom ideas for encouraging thinking \& feeling. Buffalo NY: DOK Publishers, 1970.

[11] D. Treffinger, Individualized education program plans for gifted, talented \& creative students // Developing IEPs for gifted / talented. Ventura CA: Office of the Ventura County Superintendent of Schools, 1979.

[12] J. Dewey, Experience \& Education, N.Y.: Macmillan, 1938.

[13] V. P. Vakhterov, Selected pedagogical works, M .: Pedagogika, 1987.

[14] W. Barbe, E. Frierson, Teaching the gifted - a new frame of reference // W. Barbe \& J.Renzulli (Eds). Psychology \& education of the gifted. N.Y.: Irvington Publishers, 1975.

[15] T. Newland, The gifted in socio-educational perspective, Englewood Cliffs NJ: Prentice-Hall, 1976. 
[16] J. Kagan, Personality \& the learning process, J. Kagan (ed.). Creativity \& learning. Boston: Houghton Mifflin, 1967.

[17] J. F. Feldhusen, C.Willard-Holt, Gender differences in classroom interactions \& career aspirations of gifted students // Contemporary Educ. Psychol., 1992, Vol.18, pp.355-362.

[18] D. Treffinger, Individualized education program plans for gifted, talented \& creative students, Developing IEPs for gifted / talented, Ventura CA: Office of the Ventura County Superintendent of Schools, 1979.

[19] N. B. Shumakova, Interdisciplinary approach to the teaching of gifted children, Questions of Psychology, 1996, N 3, pp. 34-43.

[20] N. B .Shumakova, Teaching and development of gifted children, Moscow: MPSI and NPI "MODEC", 2003.

[21] S. Kaplan, Curricular \& programmatic concerns: educating the preschool/ primary gifted \& talented. Venture CA: Venture Country Superintendent of Schools, 1980.

[22] K. Abroms, J. Gollin, Developmental study of gifted preschool children \& measures of psychosocial giftedness // Exceptional Children, 1980, N 46, pp. 334-341.

[23] J. Flavell, P. Botkin, C. Fry, J. Wright, P. Jarvis, The development of role-taking \& communication skills in children. N.Y.: Willey, 1968.

[24] K. Abroms, J. Gollin, Developmental study of gifted preschool children \& measures of psychosocial giftedness // Exceptional Children, 1980, N 46, pp. 334-341.

[25] E. L. Yakovleva, Psychological bases of development of creative potential of the schoolboy's personality // Development of creative potential of the schoolboy's personality. M, 1996, pp. 6-16.

[26] J. Nelson, D.Cleland, The role of the teachers of the gifted \& creative children // W.Barbe \& J.Renzulli (Eds.) Psychology \& education of the gifted. N.Y.: Irvington Publishers, 1975.

[27] V. Enrlich, Astor program for gifted children: Prekindergarten through grade three. N.Y.: Teacher`s College. Columbia University, 1978.

[28] J. S. Renzulli, The three-ring conception of giftedness: A developmental model for creative productivity // Sternberg R.I., Davidson J.E. (eds.). Conceptions of giftedness. Cambridge: Cambr. Univ. Press, 1986, pp. 53-92.

[29] M. L. Ivleva, N. L. Bagramiants, V. Y. Ivlev, M. B. Oseledchik, Methodological principles of the study of the philosophical foundations of psychological conceptions of giftedness, Proceedings of the 2016 Third International Conference on Education, Language, Art and Inter-cultural Communication (ICELAIC 2016), Advances in Social Science, Education and Humanities Research. Paris: Atlantis Press, 2017. Vol. 40 pp. 48-52.

[30] M. Karnes, A. Schwedel, M.Williams, Combining instructional models for young gifted children // Teaching Exceptional Children. 1983. No. 14 (3), pp. 128-135.

[31] B. S. Bloom, L. Sosniak, Talent development vs. schooling // Educational Leadership, 1981, No. 39 (2), pp. 86-94.

[32] C. Takacs, They don't get gifted until 4th grade: what parents can do until then, Roeper Review, 1982, No. 4, pp. 43-45.

[33] N. B. Shumakova, Interdisciplinary approach to the teaching of gifted children / / Questions of Psychology, 1996, No. 3, pp. 34-43.

[34] N. B. Shumakova, Teaching and development of gifted children, Moscow: MPSI and NPI "MODEC", 2003.

[35] E. L. Yakovleva, Psychological bases of development of creative potential of the schoolboy's personality, Development of creative potential of the schoolboy's personality, M, 1996, pp. 6-16.

[36] M. Shure, G. Spivack, M. Jaeger, Problem-solving thinking \& adjustment among disadvantaged preschool children // Child Development, 1971, No 42, pp. 1791-1803.

[37] A. M. Matiushkin, The concept of creative endowments // Questions of psychology, 1989, №6, pp. 29-33. 